\title{
TWO NEW FEATHER MITES OF THE GENUS PROCTOPHYLLODES ROBIN (ACARIFORMES: PROCTOPHYLLODIDAE) ASSOCIATED WITH PASSERINES (AVES: PASSERIFORMES) IN THE RUSSIAN FAR EAST
}

\section{Sergey V. Mironov}

\author{
Zoological Institute of the Russian Academy of Sciences, Saint Petersburg, Russia \\ e-mail: sergei.mironov@zin.ru
}

\begin{abstract}
Two new species of the feather mite genus Proctophyllodes (Proctophyllodidae: Proctophyllodinae) are described from passerines in the Primorye Territory, Russia: Proctophyllodes bochkovi sp. n. from the blue-and-white flycatcher Cyanoptila cyanomelana (Temminck) (Muscicapidae) and P. cyanopicae sp. n. from the azure-winged magpie Cyanopica cyanus (Pallas) (Corvidae). Proctophyllodes bochkovi belongs to the caulifer species group. It differs from the most similar species, $P$. cotyledon Trouessart, 1899, in having the genital arch not extending to the level of epimerites IIla, the terminal lamellae symmetrical with pennate venation and by the absence of the paragenital apodemes in males, and in having a longer lobar region (78-88 $\mu \mathrm{m})$ in females. Proctophyllodes cyanopicae belongs to the musicus group and is readily distinguished from the most similar species, P. picae (Koch, 1841), in having the hysteronotal shield with well pronounced circular lacunae, and setae $g$ situated closer to the level of setae ps 3 than to the genital arch tips in males, and in having the terminal cleft shaped as a longitudinal rectangle 50-55 $\mu \mathrm{m}$ long in females.
\end{abstract}

KEY WORDS: Feather mites, Proctophyllodidae, Proctophyllodes, Passeriformes, Russian Far East, systematics.

DOI: $10.21684 / 0132-8077-2019-27-2-151-164$

\section{INTRODUCTION}

Proctophyllodes Robin, 1868 (Analgoidea: Proctophyllodidae) is the most species-rich genus among all feather mite families. To date, including the two new species described herein, the genus includes 177 species (Vitzthum 1922; Gaud and Mouchet 1957; Fritsch 1961; Atyeo and Braasch 1966; Gaud and Atyeo 1996; Mironov 2012, 2017; Mironov and OConnor 2014; Wang et al. 2014). Like most other representatives of the family Proctophyllodidae, members of the genus Proctophyllodes inhabit feathers with large and firm vanes (the remiges, greater coverts of the wings) and rectrices - where they are located in narrow corridors on the ventral surfaces of vanes. Mites of the genus Proctophyllodes are almost entirely restricted to birds of the order Passeriformes and have been recorded from representatives of 50 passerine families (as classified by Gill and Donsker 2019). There are only three Proctophyllodes species that do not occur on passerines, each of which is associated with a particular host group from the orders Apodiformes (Trochilidae), Charadriiformes (Scolopacidae: Scolopax) and Piciformes (Picidae: Jynx) (Atyeo and Braasch 1966; Kanegae et al. 2008; Mironov 2012; Yamasaki et al. 2018).

The latest taxonomic revision of Proctophyllodes carried out by Atyeo and Braasch (1966) provided (re)descriptions of all 121 species known at that time according to a uniform scheme and supplied them with a detailed synonymy and hostassociation data. This fundamental monograph is the main publication on systematics of this genus and presently is the only key for identification of its species. An updated world checklist of 162 Proctophyllodes species and exhaustive references to papers, containing descriptions of new species published after the revision by Atyeo and Braasch (1966), were presented by Mironov (2012). In the subsequent years, only thirteen new species were added to the world fauna (Mironov and OConnor 2014; Wang et al. 2014; Mironov 2017; Mironov et al. 2017). Several new species were also illustrated in the thesis work by $\mathrm{Su}$ (2014), but their names are nomina nuda and unavailable.

The systematics of the genus Proctophyllodes, including its subdivision into species groups and species identification, is almost completely based on the structures of the opisthosoma and genital region in males, while features of females serve only as an additional complex of characters. Atyeo and Braasch (1966) proposed a subdivision of this vast genus into ten species groups based on morphological characteristics of males. Since then, two more species groups, caulifer and mecistocaulus, have been established within this genus (Gaud and Fain 1990; Mironov and Kopij 1996).

The genus Proctophyllodes is one of a few feather mite genera, in which inter- and intragenic phylogenetic relationships have been analyzed based on molecular data. Recent phylogenetic studies, based on six genes of 133 proctophyllodid taxa (Klimov et al. 2017a, 2017b), have 
shown that Proctophyllodes is one of the most derived genera constituting the crown of the subfamily Proctophyllodinae and confirmed monophyly of most species groups, previously established by classical taxonomic methods. Nevertheless, these works have expectedly shown that this genus appears paraphyletic in relation to the much less species-rich but morphologically highly derived proctophyllodine genera Monojoubertia Radford, 1950 and Joubertophyllodes Atyeo et Gaud, 1971. In addition, these phylogenetic studies revealed several lineages, deserving of treatment as new species-groups, and re-arranged the species composition of some groups previously established by Atyeo and Braasch (1966).

The present work continues an ongoing investigation of the diversity and taxonomy of feather mites associated with passerines in the Russian Far East (Mironov 2011; Mironov et al. 2012), a region of Russia that is almost unexplored in this aspect, and provides descriptions of two new Proctophyllodes species found on two passerine species that are common in this area.

\section{MATERIALS AND METHODS}

The material used in the present work was collected in the course of parasitological surveys conducted in Primorye Territory, the most southeastern area of the Russian Far East, during autumn migrations of birds in 2007, 2016 and 2019. Passerine birds were captured with mist-nets, then identified, banded and finally checked for the presence of feather mites and other ectoparasites. Live birds were briefly placed under a stereomicroscope, and the detected feather mites were collected with a preparation needle or fine forceps and fixed in tubes with $96 \%$ ethanol. After processing, the captured birds were released back to the wild. In the laboratory, feather mites were mounted on slides in Hoyer's medium according to the standard technique for small mites (Krantz and Walter 2009). Investigation of the mite specimens and drawings were made using Leica DM 2500 and DM 5000B light microscopes equipped with DIC illumination and a camera lucida.

The description of species and measuring techniques follow the current schemes used for proctophyllodine feather mites (Hernandes et al. 2007; Badek et al. 2008; Mironov and GonzálezAcuña 2009; Mironov 2012, 2017; Mironov et al. 2012, 2017). General morphological terms, as well as leg and idiosomal chaetotaxy follow Gaud and
Atyeo (1996) with minor corrections to the nomenclature of coxal setae by Norton (1998). All measurements are in micrometres $(\mu \mathrm{m})$. The measuring techniques used for some structures are included in the descriptions.

The taxonomic system and scientific names of birds follow Gill and Donsker (2019). Abbreviations used in collection numbers and type material depositories include the following: BMOC-Museum of Zoology of the University of Michigan, Ann Arbor, USA; ZISP and SVM-Zoological Institute of the Russian Academy of Sciences, Saint-Petersburg, Russia.

\section{SYSTEMATICS}

\section{Family Proctophyllodidae Trouessart et Mégnin, 1884}

Subfamily Proctophyllodinae Trouessart et Mégnin, 1884

Genus Proctophyllodes Robin, 1868

\section{Proctophyllodes bochkovi sp. n.}

(Figs. 1-4)

Type material. Male holotype (ZISP 8473), 9 male and 10 female paratypes (ZISP 8474-8492) from Cyanoptila cyanomelana (Temminck, 1829) (Muscicapidae) (SVM-07-0826-8), Russia, Primorye Territory, Partizansky District, Novolitovsk, 9 $\mathrm{km} \mathrm{N}, 42^{\circ} 51^{\prime} 40^{\prime \prime} \mathrm{N} ; 132^{\circ} 53^{\prime} 5.5^{\prime \prime} \mathrm{E}, 26$ August 2007 , leg. S.V. Mironov.

Depository. Male holotype, 6 male and 6 female paratypes - ZISP, remaining paratypes-BMOC.

Additional material. 9 males and 9 females (ZISP 8493-8510) from Cyanoptila cyanomelana (SVM-07-0916-3/1), Russia, Primorye Territory, Partizansky District, Novolitovsk, $9 \mathrm{~km} \mathrm{~N}$, $42^{\circ} 51^{\prime} 40^{\prime \prime} \mathrm{N}$; $132^{\circ} 53^{\prime} 5.5^{\prime \prime} \mathrm{E}, 16$ September 2007 , leg. S.V. Mironov; 8 males and 8 females (ZISP 8512-8527) from C. cyanomelana (SVM-19-08153/1), Russia, Primorye Territory, Anuchinsky District, Vinogradovka, $2 \mathrm{~km} \mathrm{~N}, 43^{\circ} 46^{\prime} 50.5^{\prime \prime} \mathrm{N}$, $132^{\circ} 56^{\prime} 01.3^{\prime \prime} \mathrm{E}, 15$ August 2019, leg. S.V. Mironov.

Description. Male (holotype, range for 9 paratypes in parentheses) (Figs. 1, 3A-D, 4A-D). Idiosoma, length $\times$ width, $285(275-290) \times 145(145-$ 150); length of hysterosoma 175 (175-185). Prodorsal shield: setae $v i$ absent, anterolateral extensions short and rounded, lateral margins with shallow incisions not encompassing bases of setae se, posterior corners rounded, posterior margin slightly concave, greatest length 75 (72-80), greatest width at posterior margin 87 (85-95), surface without 


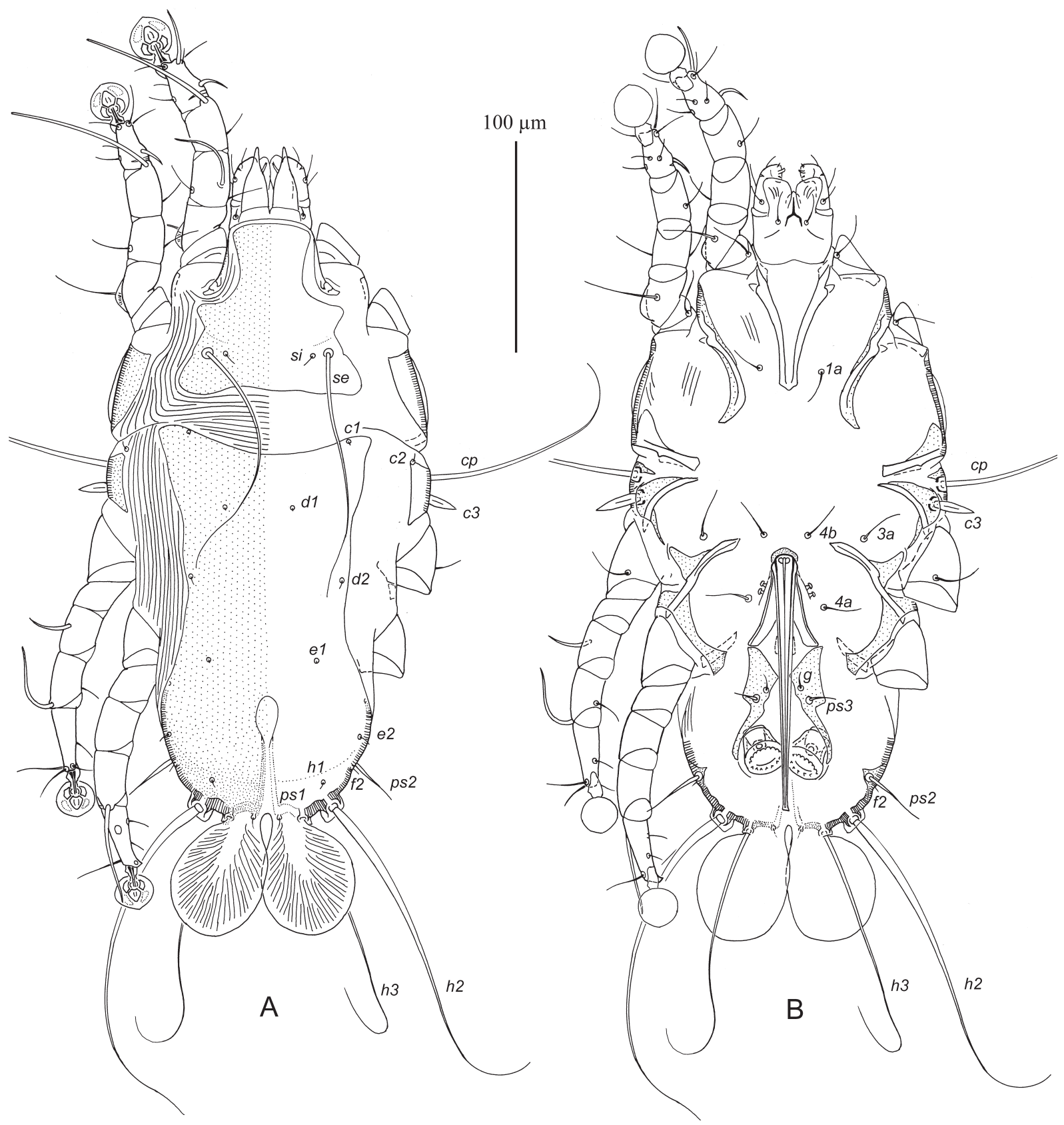

Fig. 1. Proctophyllodes bochkovi sp.n., male. A-dorsal view, B-ventral view.

ornamentation. Distance between bases of scapular setae se 57 (55-60). Scapular shields wide. Humeral shields well developed, not fused with epimerites III, touching bases of setae $c p$. Setae $c 2$ situated on anteromedial angles of humeral shields or off them. Subhumeral setae $c 3$ narrowly lanceolate, 17 (15-18) long, about 5 wide. Hysteronotal shield: anterior margin slightly concave, anterior corners acute and slightly extending laterally, length 175 (170-185), width at anterior margin 100 (92-100), surface without ornamentation. Distance between prodorsal and hysteronotal shields along midline 30 (23-30). Supranal concavity opened terminally, anterior end extending to midlength between levels of setae $e 1$ and $e 2$, length from anterior end to bases of setae ps1 60 (52-60). Posterior end of opisthosoma (posterior to setae ps 2 ) rounded. Terminal lamellae widely ovate, slightly longer than wide, slightly overlapping by inner margins, with pennate venation; length of lamellae 52 (50-55), greatest width $42(40-45)$. Distance between bases of lamellae about 5. Setae ps 1 minute. Distances between hysteronotal setae: $c 2: d 255$ (55-60), d2:e2 72 (70-75), e2:h3 40 (38-48), d1:d2 32 (30-35), el:e2 35 (30-38), h1:h3 20 (17-20), h2:h2 63 (60-65), h3:h3 35 (32-38), ps2: ps2 82 (80-85). 


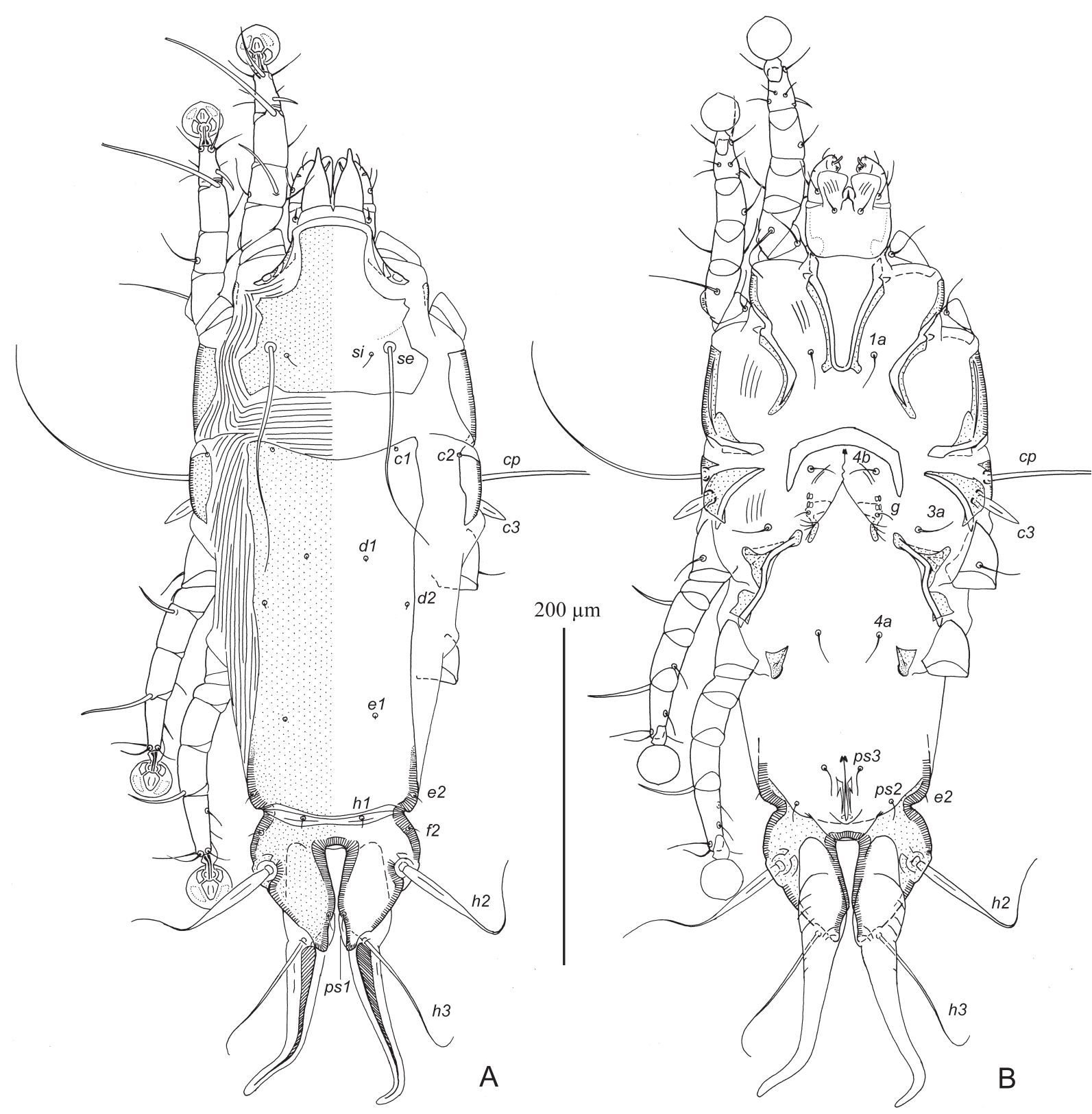

Fig. 2. Proctophyllodes bochkovi sp.n., female. A-dorsal view, B-ventral view.

Epimerites I fused into a narrow U, without lateral extensions. Epimerites IVa well developed, bases of trochanters IV flanked by entire sclerotized band. Setae $4 b$ and $3 a$ situated at same transverse level, slightly anterior to level of inner tips of epimerites IIIa. Genital arch elongated, 42 (40-44) in length, 35 (32-38) in width at base, apex slightly extending to midlevel of trochanters IV and not extending beyond epimerites IIIa tips, base at midlevel of trochanters IV. Aedeagus long sword-like, completely wrapped in genital sheath, reflected rearward from genital arch apex and almost extending to level of setae $h 2,120$ (115-120) in length; genital sheath slightly longer than aedeagus, mo- notonously attenuate apically, with asymmetric apex (Figs. 1B, 3A, B). Distance from genital arch apex to level of setae ps1 100 (95-105). Setae $4 a$ situated at midlevel of genital arch apex. Genital papillae at level of anterior half of genital arch, bases of papillae not connected. Paragenital apodemes absent. Epiandrum present, with short acute tips rarely extending to genital papillae. Opisthogastric shield represented by a pair of long longitudinal sclerites widely separated from each other; anterior part of these sclerites wide, with anterior adjoining genital arch tips, and with distinct lateral extension of variable shape (simply rectangular, claw-shaped or long bow-shaped; Figs. 3A-D); posterior ends 
Proctophyllodes species from the Russian Far East

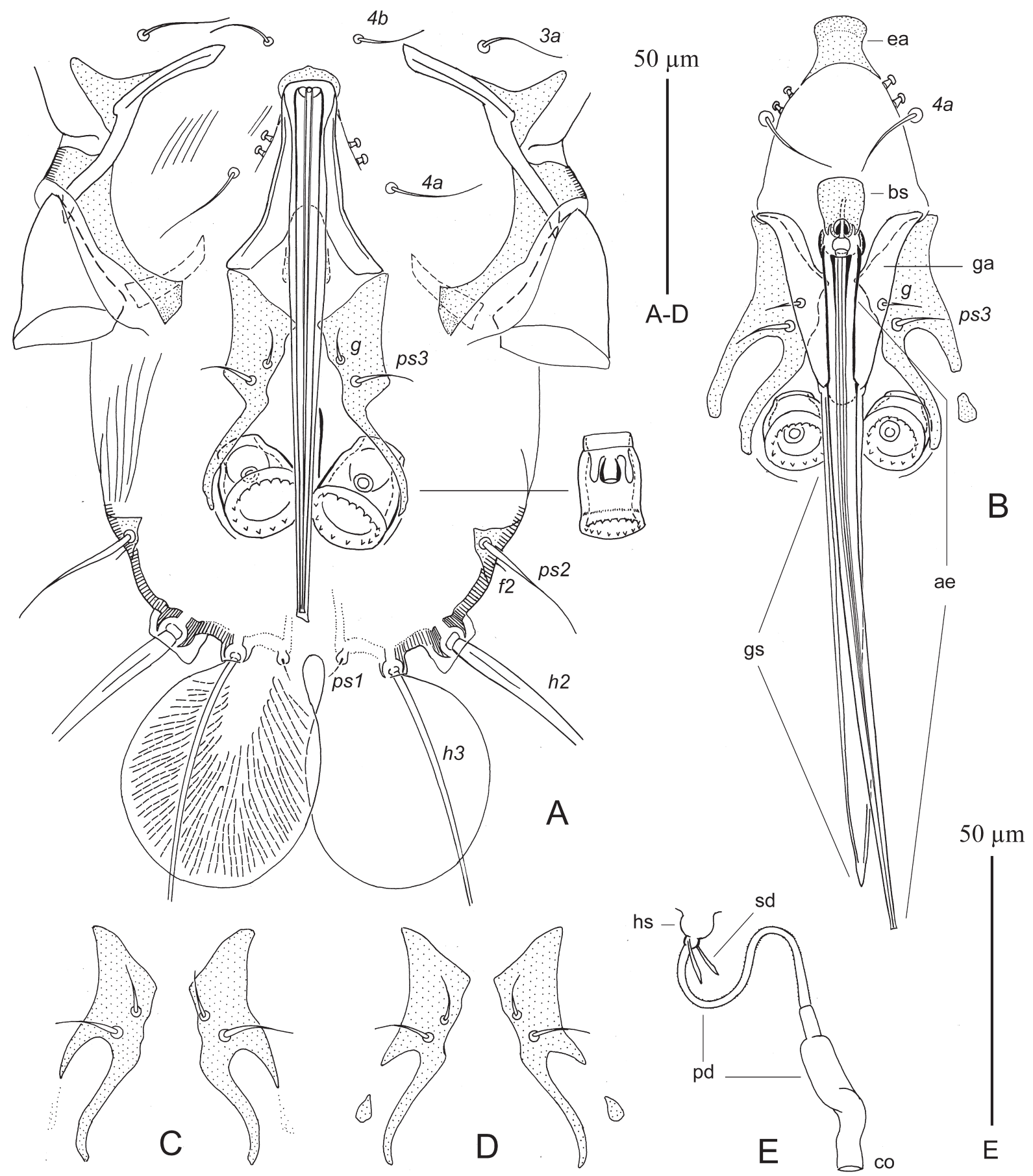

Fig. 3. Proctophyllodes bochkovi sp. n., details of genital apparatus. A-ventral view of male opisthosoma, B-genital apparatus of male in protruded position, C, D-variation of opisthogastric shield in male, E-spermatheca and spermaducts. Abbreviations: ae — aedeagus, bs — basal sclerite, co — copulatory opening, ea — epiandrum, ga — genital arch, gs - genital sheath, hs — head of spermathecal, pd — primary spermaduct, sd — secondary spermaduct.

of opisthogastric sclerites narrow bow-shaped, flanking adanal suckers laterally; greatest length of sclerites 58 (50-58), distance between outer margins of their anterior ends 37 (35-40). Accessory and postanal sclerites absent. Setae $g$ and $p s 3$ in trapezoidal arrangement, both situated on opisthogastric shields. Adanal suckers cylindrical, slightly en- larged apically, 25 (22-26) in length, 20 (19-22) in width at base, corolla with 15-17 small denticles. Distances between setal bases: $g: g 17$ (16-18), g:ps3 5 (5-6), ps3:ps3 25 (25-28), 4b:4a 32 (3034), 4a:g 38 (37-42), ps3:h3 65 (62-65).

Femora I and II without noticeable ventral crests. Genual solenidia $\sigma / \mathrm{I}$ and $\sigma$ III situated 


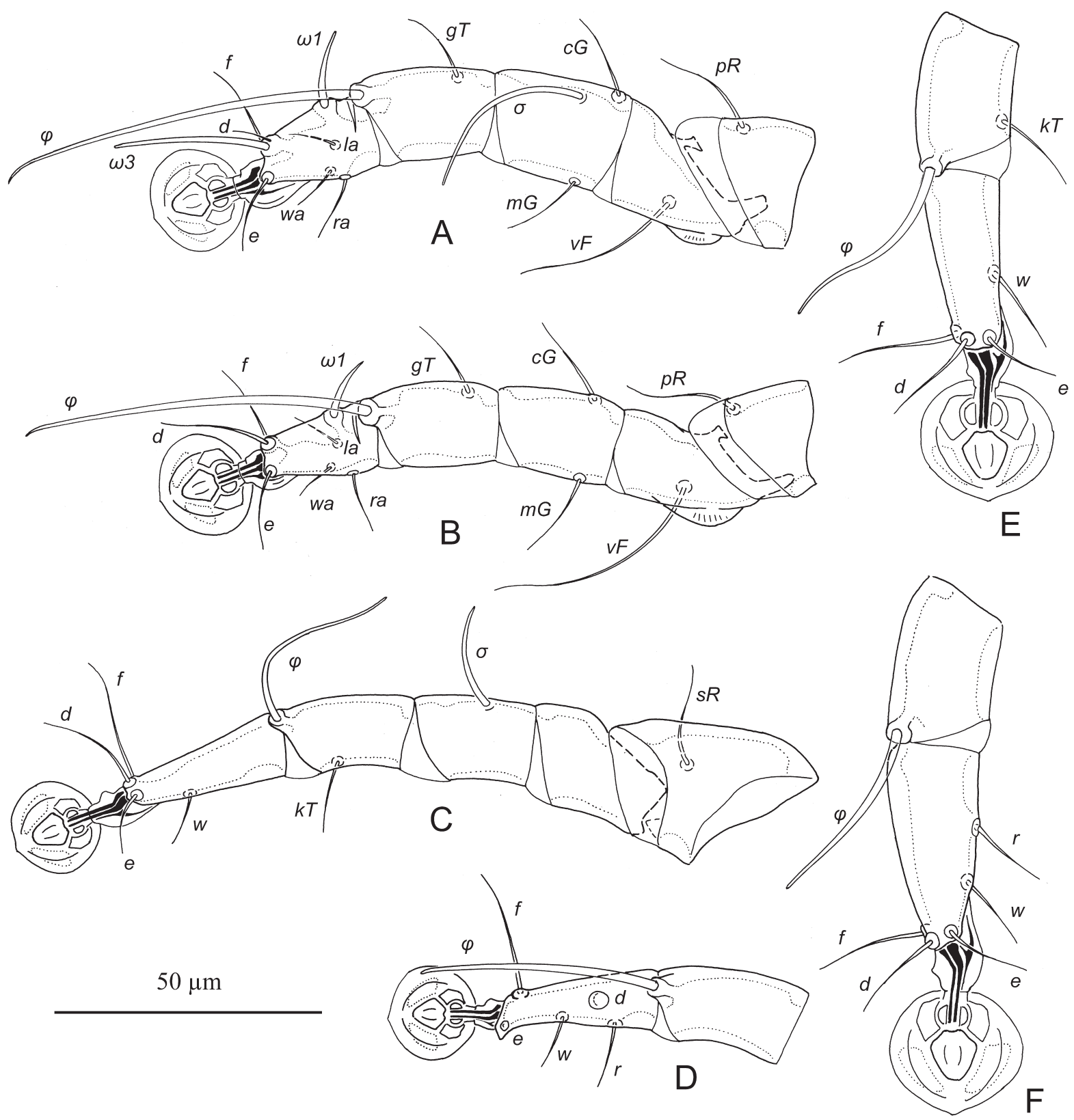

Fig. 4. Proctophyllodes bochkovi sp.n., details. A-C-legs I-III of male, respectively, D—tibia and tarsus IV of male, E, F-tibiae and tarsi III, IV of female, respectively.

slightly closer to bases of corresponding segments (Fig. 4A, C). Tarsus IV 30 (30-34) long, with angular hook-like apical extension; button-shaped seta $d$ situated in basal half of this segment and approximately two times larger in diameter than seta $e$ (Fig. 4D). Length of solenidia: $\sigma \mathrm{I} 35(35-43)$, $\sigma$ III 18 (17-20), $\varphi$ IV 45 (40-45).

Female (10 paratypes; Figs 2, 3E, 4E, F). Idiosoma, length $\times$ width, 410-445, width 165-185, length of hysterosoma 285-315. Prodorsal shield: setae $v i$ absent, anterolateral extensions short and usually bidentate, lateral margins with shallow incisions, posterior corners obliquely cut, poste- rior margin almost straight or slightly sinuous, greatest length 90-105, width 105-115 (Fig. 2A). Distance between scapular setae se 67-75. Scapular shields wide. Humeral shields not fused with epimerites III, touching bases of setae $c p$. Setae $c 2$ situated in anteromedial angles of humeral shields. Subhumeral setae $c 3$ narrowly lanceolate, 20-22 long, 6-7.5 wide. Distance between prodorsal and hysteronotal shields 35-40. Lobar region of opisthosoma distinctly separated from remaining part of hysterosoma, hysteronotal shield split into anterior and lobar parts by narrow transverse furrow but connected ventrolaterally by narrow bands. 
Anterior hysteronotal shield roughly rectangular, 205-225 in length, 95-105 in width, with anterior margin shallowly concave, with posterior margin slightly convex, surface without ornamentation. Lobar shield entire, with strongly convex lateral margins and without noticeable extensions bearing setae $h 2,78-88$ in length, $100-110$ in width. Opisthosomal lobes attenuate apically, nearly twice as long as their width at base; terminal cleft narrow hourglass-shaped, 60-68 in length, 13-18 in width in anterior part. Supranal concavity absent. Setae $h 1$ on narrow band of soft tegument between anterior hysteronotal and lobar shields. Setae $p s 1$ on lateral margins of terminal cleft. Setae $h 2$ with enlargement in basal half and with long apical filament, 95-115 long, 7-7.5 wide; setae $h 3$ filiform, 75-95 long, about 3/4 the length of terminal appendages. Distance between dorsal setae: $c 2: d 2$ 80-90, d2:e2 105-120, e2:h2 42-48, h2:h3 40-45, d1:d2 30-38, e1:e2 37-50, h1:h2 30-35, h2:ps1 24-32, h1:h1 35-38, h2:h2 80-85.

Epimerites I shaped as in males, with short lateral extensions. Epimerites IVa small triangular. Epigynum nearly semicircular, tips almost extending to level of genital papillae, lateral extensions not developed, length 32-40, width 68-75. Copulatory opening situated immediately posterior to anal opening and covered with posterior ends of anal flaps. Head of spermatheca as small spheroid; secondary spermaducts 6-8 long, situated on mall spherical enlargement of proximal end of primary spermaduct; proximal half of primary spermaduct narrow; distal half of primary spermaduct nearly 3 times wider than proximal one, transitional piece shaped like the neck of a bottle (Fig. 3E). Translobar apodemes wide, connected to each other anterior to terminal cleft. Setae $p s 2$ situated at level of posterior half of anal opening and widely separated from each other; distance between pseudanal setae: ps2:ps2 55-58, ps3:ps3 20-24, ps2:ps3 20-23.

Legs I and II as in males, femur II with narrow ventral crests. Genual solenidion $\sigma$ III situated in basal part of segment. Length of solenidia: $\sigma \mathrm{I}$ 42-48, $\sigma$ III $22-25, \varphi$ III 40-45, $\varphi$ IV 32-35. Legs IV with ambulacral discs extending slightly beyond level of setae $h 2$.

Differential diagnosis. Proctophyllodes bochkovi sp.n. belongs to the caulifer species group (Mironov and Kopij 1996; Klimov et al. 2017a) in having the genital organ (aedeagus wrapped in genital sheath) very long and extending to or beyond the posterior end of the body and by the absence of reniform accessory sclerites in males.
Within this group, the new species is most similar to $P$. cotyledon (Trouessart, 1899), which is associated with various muscicapids and timaliids in the following: in males, the epiandrum is present, the genital organ almost reaches to the posterior end of the body, and the terminal lamellae are widely lanceolate; in females, the terminal cleft is shaped as a narrow hourglass. Proctophyllodes bochkovi sp.n. differs from $P$. cotyledon in the following features. In males, the genital arch does not extend to the level of epimerites IIIa tips, the paragenital apodemes are absent, the corolla of adanal sucker bears 15-17 denticles, and the terminal lamellae are symmetrical and have pennate venation. In females, the lobar region is longer (78-88) and the anterolateral extensions of the prodorsal shield are bidentate or blunt. In males of $P$. cotyledon, the genital arch extends beyond the level of epimerites IIIa tips and even to setae $4 b$, the paragenital apodemes are present and fused with the epiandrum, each adanal sucker has numerous denticles (20-28), and the terminal lamellae are asymmetrical, cordiform, with outer margin strongly convex and with palmate venation. In females, the lobar region is about 70 long and the anterolateral extensions of the prodorsal shield are acute.

Remarks. 1. The closest species, Proctophyllodes cotyledon, was described by Trouessart (1899: 39) from a single male collected from the California Thrasher Toxostoma redivivum (Gambel, 1845) (Mimidae) in Brazil. This mite, with very characteristic features, such as the genital apparatus extending to the posterior margin of the body and the terminal lamellae resembling the embryonic seed leaf of plants (Lat. cotyledon), has never been recollected from the type host or from any other species of mockingbirds. Contrary, this species was further reported from many genera of flycatchers (Muscicapidae: Copsychus, Enicurus, Muscicapa, Phoenicurus, Saxicola, and Tarsiger), babblers (Timaliidae: Stachyris) and even fantails (Rhipiduridae: Rhipidura) in the Old World, from Europe to Malaya (Gaud 1957; Vassilev 1958; Fritsch 1961; Atyeo and Braasch 1966). Vassilev (1958) and Fritsch (1961) independently described two new species, Proctophyllodes dontchevi Vassilev, 1958 and P. cardifolius Fritsh, 1961, respectively, also having these distinctive characteristics. Both mite species were collected from the Black Redstart Phoenicurus ochruros (Gmelin, SG, 1774) in Europe. The description by Fritsch (1961: 6-10, figs. $2 \mathrm{c}, \mathrm{d}, 3-5)$ included very careful and detailed illustrations. In their revision of the genus Procto- 
phyllodes, Atyeo and Braasch (1966) synonymized $P$. dontchevi and P. cardifolius with P. cotyledon and concluded that the primary record from $T$. redivivum was obviously a museum contamination, and that this mite species is distributed on muscicapids and related taxa in the Old World. Atyeo and Braasch (1966) examined many samples that referred to $P$. cotyledon, including the type specimen, and noted a morphological variability between the mites collected from different hosts and areas of the Old World. These differences consisted in the presence and the pattern of lacunae on dorsal shields in both sexes and as well in the size of terminal lamellae in males. Nevertheless, these authors were not able to determine the most likely host of the $P$. cotyledon type specimen. In their redescription of $P$. cotyledon, the drawing of the male was based on the holotype of this species (from $T$. redivivum), but that for the female was based on the paratype of $P$. dontchevi. From the modern point of view, it is quite clear that Atyeo and Braasch certainly dealt with a complex of closely related species. It is necessary to note that the drawing of the $P$. cotyledon male provided by these authors does not completely correspond to that of P. cardifolius from Phoenicurus ochruros given by Fritsch (1961) and to the specimens from this host deposited in the collection in the Zoological Institute (ZISP), in particular with regard to the lateral contour of the opisthogastric shields. This allows the conclusion that the type specimen of $P$. cotyledon was not from $P$ h. ochruros but from some other as yet undetermined host. In the differential diagnosis above, P. bochkovi was compared with the specimens of $P$. cotyledon from Ph. ochruros, the most common host of this species in Europe.

2. Proctophyllodes bochkovi was also found on Cyanoptila cyanomelana in South Korea (personal communication of Y.-D. Han, Inha University, Incheon, South Korea).

Etymology. The species is named after Andrei (André) Vladimirovich Bochkov (1968-2018)—a world-renowned acarologist and my very good friend and colleague, who passed away so early.

\section{Proctophyllodes cyanopicae sp.n.}

(Figs. 5-7)

Type material. Male holotype (ZISP 8528), 10 male and 11 female paratypes (ZISP 8529-8549) from Cyanopica cyanus (Pallas, 1776) (Corvidae) (SVM07-0828-8), Russia, Primorye Territory, Partizansky District, Novolitovsk, $9 \mathrm{~km} \mathrm{~N}, 42^{\circ} 51^{\prime} 40^{\prime \prime} \mathrm{N}$; $132^{\circ} 53^{\prime} 5.5^{\prime \prime}$, 28 August 2007, leg. S.V. Mironov.
Depository. Male holotype, 8 male and 8 female paratypes - ZISP, remaining paratypes-BMOC.

Additional material. 4 males and 4 females (ZISP 8461-8467) from Cyanopica cyanus (SVM16-0829-2), Russia, Primorye Territory, Ussuriysky district, Aleksey-Nikolskoye, $3 \mathrm{~km} \mathrm{~S}$, $43^{\circ} 48^{\prime} 49.8^{\prime \prime} \mathrm{N} \mathrm{131}{ }^{\circ} 32^{\prime} 30^{\prime \prime} \mathrm{E}, 29$ August 2016, leg. S.V. Mironov; 15 males and 20 females (ZISP 8550-8584) from C. cyanus (SVM-19-0824-1/1), Russia, Primorye Territory, Spassky District, Gay-


leg. S.V. Mironov.

Description. Male (holotype, range for 8 paratypes in parentheses) (Figs. 5, 6A-D). Idiosoma, length $\times$ width, $265(260-280) \times 135(135-160)$; length of hysterosoma 170 (160-175). Prodorsal shield: setae $v i$ absent, anterolateral extensions short and acute, lateral margins with shallow incisions not encompassing setae se, posterior corners obliquely cut, posterior margin with wide and short median extension, greatest length 75 (72-78), greatest width at posterior margin 80 (72-80), surface without ornamentation. Distance between bases of scapular setae se 55 (52-65). Scapular shields wide. Humeral shields well developed, not fused with epimerites III, touching bases of setae $c p$. Setae $c 2$ situated in anteromedial angles of humeral shields. Subhumeral setae $c 3$ narrowly lanceolate, 17 (15-18) long, about 5 (4-5) wide. Distance between prodorsal and hysteronotal shields 23 (22-28). Hysteronotal shield: anterior margin slightly concave, anterior corners acute and slightly extending laterally, length 175 (165-180), width at anterior margin 90 (85-95), entire surface with numerous circular and ovate lacunae, up to 5 in diameter. Supranal concavity opened terminally, anterior end extending slightly beyond level of setae $e 2$, length from anterior end to bases of setae ps 138 (37-42). Posterior end of opisthosoma between setae $e 2$ roughly trapezoidal. Terminal lamellae ovate, with widely rounded posterior margin, slightly overlapping by inner margins, with pennate venation; length of lamellae 48 (37-50), greatest width 35 (30-38). Distance between bases of lamellae about 2.5. Setae $p s 1$ minute. Distances between hysteronotal setae: $c 2: d 263(62-65), d 2: e 265$ (62-65), e2:h3 35 (32-38), d1:d2 35 (32-38), e1:e2 35 (20-40), h1:h3 25 (22-26), h2:h2 55 (52-60), $h 3: h 338$ (34-38), ps2: ps2 65 (62-70).

Epimerites I fused into a narrow U, without lateral extensions. Epimerites IVa well developed, bases of trochanters IV not flanked by sclerotized band. Setae $4 b$ situated posterior to level of tips of 


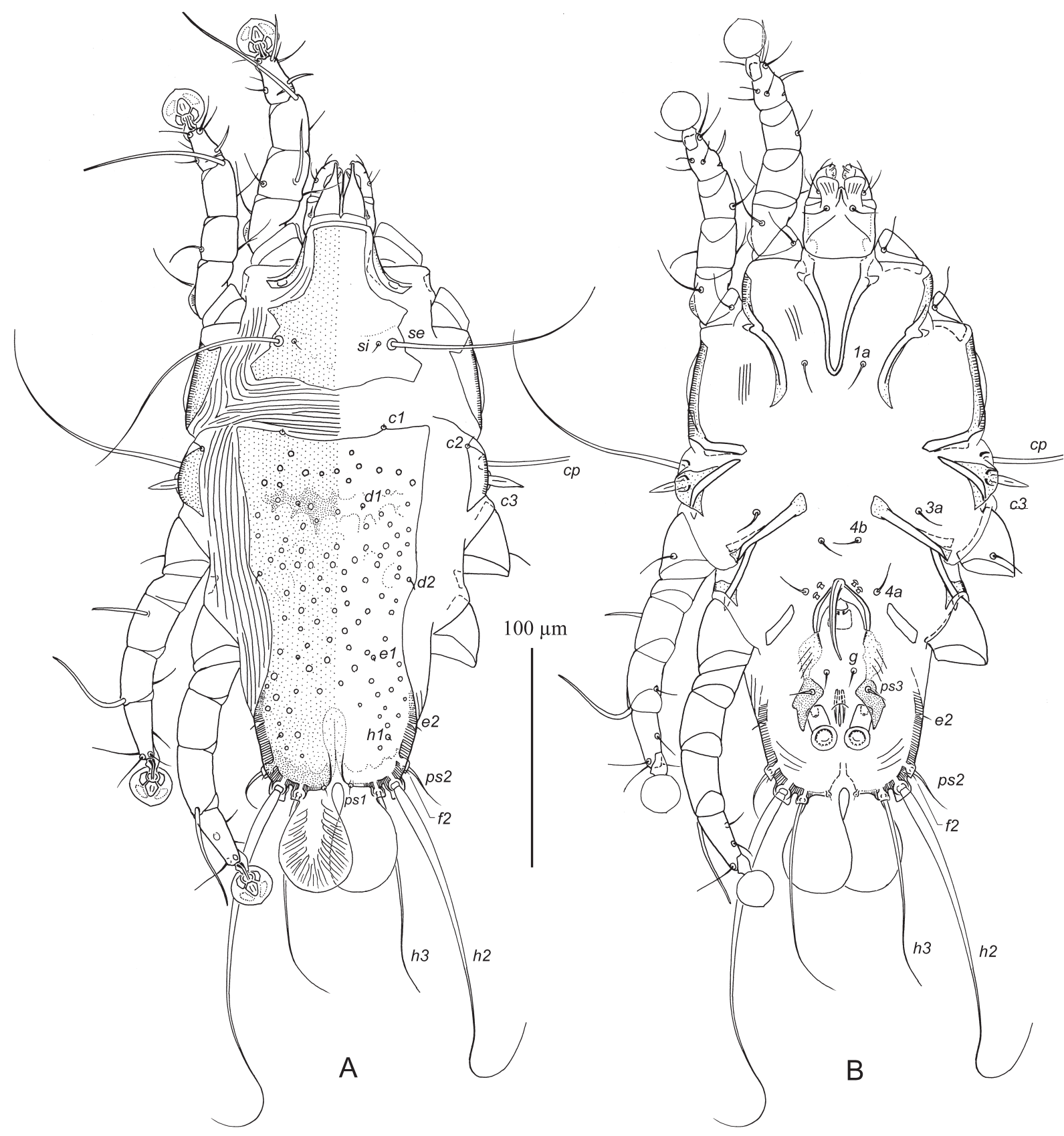

Fig. 5. Proctophyllodes cyanopicae sp. n., male. A-dorsal view, B-ventral view.

epimerites IIIa and setae $3 a$. Genital arch of moderate size, 25 (25-88) in length, 28 (25-28) in width, genital arch apex slightly extending beyond level of anterior margins of trochanters IV, base of genital arch at midlevel of trochanters IV. Aedeagus stylet-like, completely wrapped in genital sheath, slightly curved, reflected rearward immediately from genital arch apex, almost extending to setae $g, 25$ (24-26) in length; genital sheath strongly tapering apically and equal in length to aedeagus (Fig. 7A). Distance from genital arch apex to level of setae ps 198 (97-110). Setae $4 a$ and genital papillae situated at level of genital arch apex.
Bases of genital papillae not connected. Paragenital apodemes absent. Epiandrum absent. Opisthogastric shield: represented by a pair of longitudinal sclerites with irregular margins and widely separated from each other, anterior ends of these sclerites adjoining genital arch tips, posterior halves of opisthogastric sclerites noticeably more strongly sclerotized than anterior ones, posterior ends extending to and laterally flanking adanal suckers; greatest length of sclerites 42 (42-50), distance between outer margins of their anterior parts 38 (35-40). Setae $g$ and $p s 3$ in trapezoidal arrangement; setae ps 3 situated on opisthogastric shields, 


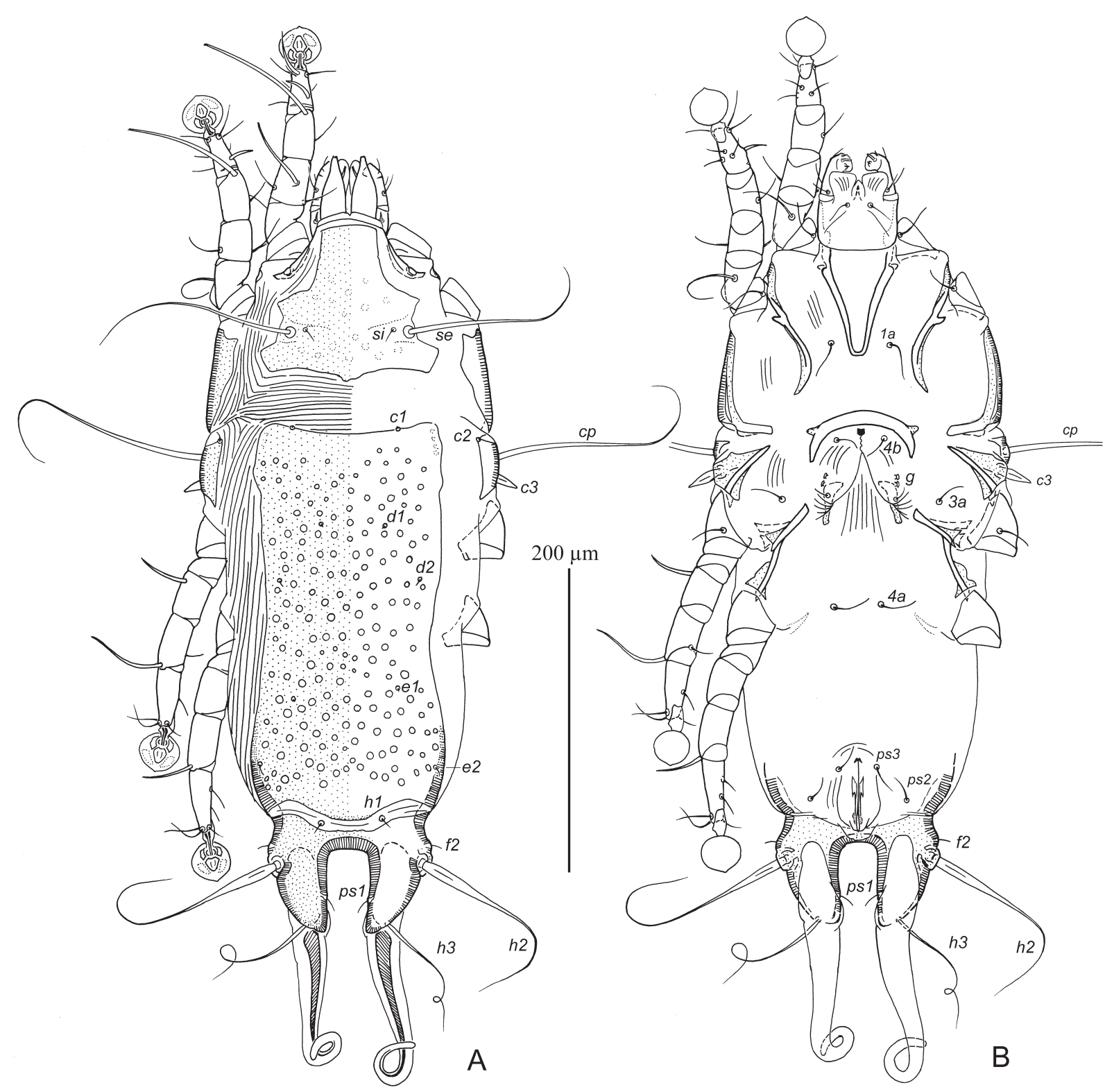

Fig. 6. Proctophyllodes cyanopicae sp.n., female. A-dorsal view, B-ventral view.

setae $g$ on soft tegument between these shields. Adanal suckers cylindrical, 25 (22-26) in length, 13 (11-13) in width; corolla thickened, with 14-16 small denticles. Accessory and postanal sclerites absent. Distances between setal bases: $g: g 12$ (10-13), g:ps3 8 (7.5-10), ps3:ps3 25 (22-26), $4 b: 3 a 25$ (23-27), 4b:4a 15 (10-15), 4a:g 38 (34-38), ps3:h3 50 (50-55).

Femora I and II without noticeable ventral crests. Genual solenidia $\sigma l \mathrm{I}$ and $\sigma$ III situated slightly closer to bases of corresponding segments (Fig. 7B, C). Tarsus IV 30 (30-35) long, without apical process; button-shaped seta $d$ situated at midlevel of this segment and approximately 2 times larger in diameter than button-shaped seta $e$ (Fig.
7E). Length of solenidia: $\sigma \mathrm{I} 25$ (25-30), $\sigma$ III 18 (17-20), $\varphi$ IV 43 (42-45).

Female (10 paratypes; Figs. 6, 7G, F): Idiosoma, length $\times$ width, 465-480 $\times 190-205$, length of hysterosoma 320-330. Prodorsal shield shaped as in males, 100-105 long, 115-125 long, surface can bear barely distinct lacunae (Fig. 6A). Distance between bases of scapular setae se 78-85. Scapular shields wide. Humeral shields not fused with epimerites III, touching bases of setae $c p$. Setae $c 2$ situated in anteromedial angles of humeral shields. Subhumeral setae $c 3$ lanceolate, 20-23 long, 7-7.5 wide. Lobar region of opisthosoma separated from remaining part of hysterosoma, hysteronotal shield split into anterior and lobar 
Proctophyllodes species from the Russian Far East

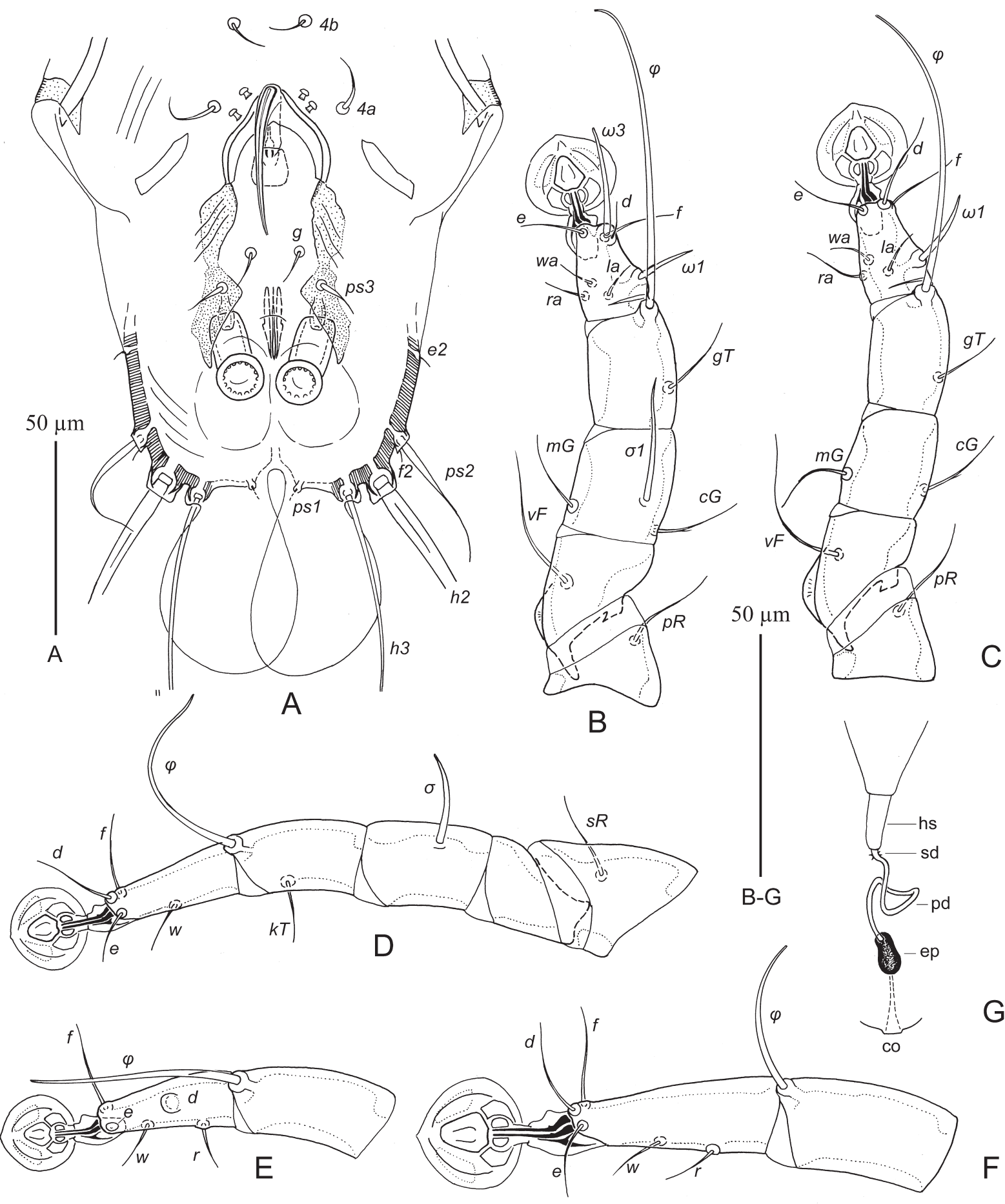

Fig. 7. Proctophyllodes cyanopicae sp.n., details. A-ventral view of male opisthosoma, B-D-legs I-III of male, respectively, E-tibia and tarsus IV of male, F-tibia and tarsus IV of female, G-spermatheca and spermaducts. Abbreviations: co — copulatory opening, ep — enlargement of primary spermaduct, hs - head of spermathecal, pdprimary spermaduct, sd—secondary spermaduct.

parts by narrow transverse furrow, but remains connected ventrolaterally by narrow sclerotized bands. Distance between prodorsal and hysteronotal shield 30-45. Anterior hysteronotal shield roughly rectangular, 250-260 in length, 120-125 in width, anterior margin shallowly concave, pos- terior margin slightly convex medially, entire surface with numerous circular and ovate lacunae up to 7 in diameter. Lobar shield entire, $77-83$ in length, 105-115 in width at level of short lateral extensions. Opisthosomal lobes slightly narrowed apically, with length 1.2-1.3 times exceeding their 
width at base; terminal cleft rectangular, $50-55$ in length, 27-30 in width in at level of setae $p s 1$. Supranal concavity absent. Setae $h l$ on narrow band of soft tegument between anterior hysteronotal and lobar shields. Setae $p s 1$ on lateral margins of terminal cleft. Setae $h 2$ with spindle-shaped enlargement in basal part and with long apical filament, $120-140$ long, 7-7.5 wide; setae $h 3$ filiform, 85-100 long, about 2/3 the length of terminal appendages. Distance between dorsal setae: $c 2: d 2$ 92-98, d2:e2 120-125, e2:h2 55-62, h2:h3 42-48, d1:d2 35-40, e1:e2 50-58, h1:h2 27-30, h2:ps1 22-25, h1:h1 38-40, h2:h2 95-100.

Epimerites I shaped as in males. Epimerites IVa rudimentary, barely sclerotized. Epigynum short, nearly semicircular, tips not extending to level of genital papillae, lateral extensions well developed, length 32-40, width 70-75. Copulatory opening situated posterior to anal opening, near margin of terminal cleft. Head of spermatheca cylindrical; secondary spermaducts extremely short; distal part of primary spermaduct with ovate or pyriform fragment having strongly thickened and heavily sclerotized wall (Fig. 7G). Translobar apodemes wide, connected to each other anterior to terminal cleft. Setae $p s 2$ situated at level of posterior half of anal opening and widely separated from each other; distance between pseudanal setae: $p s 2: p s 2$ 65-65, ps3:ps3 25-27, ps2:ps3 17-23.

Legs I and II as in males, femur II with almost indistinct ventral crests. Genual solenidion $\sigma \mathrm{III}$ situated in basal part of segment. Length of solenidia: $\sigma \mathrm{I} 37-40, \sigma \mathrm{III} 27-33, \varphi \mathrm{III} 48-52, \varphi \mathrm{IV} 30-35$. Legs IV with ambulacral discs extending to level of setae $h 2$.

Differential diagnosis. Proctophyllodes cyanopicae sp.n. belongs to the musicus species group (Atyeo and Braasch 1996) in having, in males, the opisthogastric shield split into two longitudinal widely separated pieces, the genital sheath of moderate length without terminal bifurcation and setae $p s 3$ situated on the opisthogastric shields. Within this group, the new species is most similar to $P$. picae (Koch, 1841) described from the Eurasian magpie Pica pica (Linnaeus, 1758) (Corvidae) in the following: in males, the anterior and posterior parts of the opisthogastric shield are weakly connected, and the genital sheath extends almost to the level of setae $g$; in females, the hysteronotal shield bears numerous ovate lacunae. Proctophyllodes cyanopicae differs from $P$. picae by the following features. In males of $P$. cyanopicae, the hysteronotal shield bears well defined ovate lacunae, setae $g$ are closer to the level of setae $p s 3$ than to the level of genital arch tips, the anterior ends of the opisthogastric shields lack triangular extensions, the adanal suckers have 15-17 denticles, and setae $c 3$ are narrowly lanceolate. In females of $P$. cyanopicae, the terminal cleft is rectangular, 50-55 long, and the lacunae on the anterior hysteronotal shield are large, up to 7 in diameter. In males of $P$. picae, lacunae on the hysteronotal shield are absent or barely distinct, setae $g$ are situated either closer to the genital arch tips than to setae $p s 3$ or equidistant from these levels, the anterior ends of opisthogastric shields have anterolateral angular extensions, the adanal suckers bear 20-22 denticles, and setae $c 3$ are spiculiform. In females of $P$. picae, the terminal cleft is trapezoidal, slightly divergent posteriorly, 28-32 long, and the lacunae on the anterior hysteronotal shield are small, 2-3 in diameter.

Etymology. The specific epithet is derived from the generic name of the type host and is a noun in the genitive case.

\section{ACKNOWLEDGEMENTS}

The author thanks Dr. Olga P. Valchuk (Institute of Biology and Soil Sciences of the Russian Academy of Sciences, Vladivostok), the head of the bird banding field camp near Novolitovsk, for the opportunity to examine birds and collect mites. The present study was supported by the Ministry of Science and Higher Education of the Russian Federation (project No AAAA-A19-119020790133-6).

\section{REFERENCES}

Atyeo, W.T. and Braasch, N.L. 1966. The feather mite genus Proctophyllodes (Sarcoptiformes: Proctophyllodidae). Bulletin of the University of $\mathrm{Ne}$ braska State Museum, 5: 1-354.

Badek, A., Dabert, M., Mironov, S.V. and Dabert, J. 2008. A new species of the genus Proctophyllodes (Analgoidea, Proctophyllodidae) from the Cetti's warbler Cettia cetti (Passeriformes; Sylviidae) with DNA barcode data. Annales Zoologici, 58: 397-402.

Fritsch, W. 1961. Die Milbengattung Proctophyllodes Robin 1868 (Subordo Sarcoptiformes, Fam. Proctophyllodidae Mégnin et Trouessart 1883). Zeitschrift für Parasitenkunde, 21: 1-29.

Gaud, J. 1957. Acariens plumicoles (Analgesoidea) parasites des oiseaux du Maroc. I. Proctophyllodidae. Bulletin de la Société de Sciences Naturelles et Physiques du Maroc, 37: 105-136.

Gaud, J. and Atyeo, W.T. 1996. Feather mites of the World (Acarina, Astigmata): the supraspecific taxa. 
Musée Royal de l'Afrique Centrale, Annales, Sciences Zoologiques, 277: 1-193 (Pt. 1, text), 1-436 (Pt. 2, illustrations).

Gaud, J. and Fain, A. 1990. Deux espèces nouvelles d'Acariens plumicoles du genre Proctophyllodes (Analgoidea, Proctophylodidae) parasites de Passériformes africains de la famille Pycnonotidae. Bulletin de l'Institut royal des Sciences naturelles de Belgique, Entomologie, 60: 133-138.

Gaud, J. and Mouchet, J. 1957. Acariens plumicoles (Analgesoidea) des oiseaux du Cameroun. I. Proctophyllodidae. Annales de Parasitologie Humaine et Comparée, 32 (5-6): 491-546.

Gill, F. and Donsker, D. (Eds.) 2019. IOC World Bird List (v 9.2). DOI: 10.14344/IOC.ML.9.2. Accessed 20 October 2019 at https://www.worldbirdnames. org/ioc-lists/crossref/

Hernandes, F.A., Valim, M.P. and Mironov, S.V. 2007. Two new genera and five new species of the feather mite subfamily Proctophyllodinae (Astigmata: Proctophyllodidae) from suboscine birds in Brazil. Journal of Natural History, 41 (41-44): 2653-2681.

Kanegae, M.F., Valim, M., Fonseca, M.A., Marini, M.A. and Freire, N.M.S. 2008. Feather mites (Acari: Astigmata) on birds of Cerrado in Distrito Federal, Brazil. Biota Neotropica, 8:31-39.

Klimov, P.B., Mironov, S.V. and OConnor, B.M. 2017a. Convergent and unidirectional evolution of extremely long aedeagi in the largest feather mite genus, Proctophyllodes (Acari: Proctophyllodidae): evidence from comparative molecular and morphological phylogenetics. Molecular Phylogenetics and Evolution, 114 (September 2017): 212-224.

Klimov, P.B., Mironov, S.V. and OConnor, B.M. $2017 \mathrm{~b}$. Detecting ancient co-dispersals and host shifts by double dating of host and parasite phylogenies: application in proctophyllodid feather mites associated with passerine birds. Evolution, 71-10: 2381-2397.

Krantz, G. and Walter, D. (Eds.) 2009. A Manual of Acarology. $3^{\text {rd }}$ edition. Texas University Press, Lubbock. 807 pp.

Mironov, S.V. 2011. Pteroherpus surmachi sp.n., first record of the feather mite family Pteronyssidae (Acari: Analgoidea) from nuthatches (Passeriformes: Sittidae). Proceedings of the Zoological Institute RAS, 315 (4): 452-460.

Mironov, S.V. 2012. New species of the feather mite genus Proctophyllodes Robin, 1877 (Acari: Analgoidea: Proctophyllodidae) from European passerines (Aves: Passeriformes), with an updated checklist of the genus. Acarina, 20 (2): $130-158$.
Mironov S.V. 2017. Two new feather mites of the genus Proctophyllodes Robin (Acari: Proctophyllodidae) from European passerines (Aves: Passeriformes). Systematic Parasitology, 94 (2): 215-226.

Mironov, S.V. and González-Acuña, D.A. 2009. Two new species of the feather mite subfamily Proctophyllodinae (Acari: Proctophyllodidae) from suboscine birds (Aves: Passeriformes) in Chile. Acarina, 17 (2): 189-199.

Mironov, S.V. and Kopij, G. 1996. Three new species of the feather mite family Proctophyllodidae (Acarina: Analgoidea) from some South African passerine birds (Aves: Passeriformes). Acarina, 4 (1-2): 27-33.

Mironov, S.V. and OConnor, B.M. 2014. New species of the feather mite family Proctophyllodidae (Acariformes: Astigmata) from two species of mockingbirds (Passeriformes: Mimidae) in Eastern North America. Journal of Medical Entomology, 51: 529-546.

Mironov, S.V., Dabert, J. and Dabert, M. 2012. A new feather mite species of the genus Proctophyllodes Robin, 1877 (Astigmata: Proctophyllodidae) from the Long-tailed Tit Aegithalos caudatus (Passeriformes: Aegithalidae)—-morphological description with DNA barcode data. Zootaxa, 3253: 54-61.

Mironov, S.V., Literak, I., Sychra, O. and Capek, M. 2017. Feather mites of the subfamily Proctophyllodinae (Acari: Proctophyllodidae) from passerines (Aves: Passeriformes) in Costa Rica. Zootaxa, 4297 (1): 1-105.

Norton, R. (1998). Morphological evidence for the evolutionary origin of Astigmata (Acari: Acariformes). Experimental and Applied Acarology, 22: 559-594.

Su, X.-H. 2014. [Studies of taxonomy of Analgoidea in some areas of China]. Mgr. Sci. Thesis. Southwest University, Chongqing, P. R. China. 126 pp. [In Chinese with English summary]

Trouessart, E.L. (1898) 1899. Diagnoses préliminaires d'espèces nouvelles d'Acariens plumicoles. Additions et corrections à la sous-famille des Analgésinés. Bulletin de la Société d'études scientifiques d'Angers, 28: 1-62.

Vassilev, I.D. 1958. [Zwei neue Arten Analgesoidea aus Bulgarien - Proctophyllodes bureschi sp. n. und Proctophyllodes dontschevi sp.n.]. Izvestiya na Bulgurskata Akademiya na Naukite, Otdelenieto biologicheski i meditsinski nauki, 2: 25-30. [In Bulgarian with German summary]

Vitzthum, H. 1922. Acarologische Beobachtungen. 6. Reihe. Archiv für Naturgeschichte, 88: 1-86.

Wang, Z.-Y., Wang, J.-J. and Su, X.-H. 2014. Four new feather mite species of the genus Proctophyllodes 
S.V. Mironov

Robin (Astigmata: Proctophyllodidae) from China. Zoological Systematics, 39: 248-258.

Yamasaki, Y.K., Graves, E.E., Houston, R.S., OConnor, B.M., Kysar, P.E., Straub, M.H., Foley, J.E. and Tell, L.A. 2018. Evaluation of Proctophyllodes huitzilopochtlii on feathers from Anna's (Calypte anna) and Black-chinned (Archilochus alexandri) Hummingbirds: prevalence assessment and imaging analysis using light and tabletop scanning electron microscopy. PLoS ONE, 13 (2): e0191323. 